\title{
ACESSIBILIDADE AO PATRIMÔNIO CULTURAL: O CASO DO EDIFÍCIO SEDE DA CÂMARA MUNICIPAL DORECIFE.
}

\author{
Dias, Ângela Teixeira Costa (1); \\ (1) Universidade Federal da Paraíba, Especialista em Reabilitação Ambiental Sustentável \\ Arquitetônica e Urbanística pela UnB. \\ e-mail:angeladdias@hotmail.com
}

\begin{abstract}
RESUMO
A legislação brasileira indica o acesso às fontes de cultura nacional como direito de todos, garantido pelo Estado. Para atingir esse objetivo é necessário suprimir barreiras arquitetônicas, oferecendo à população condição de deslocamento com segurança e autonomia. No caso do patrimônio cultural imóvel deve-se torna-lo acessível preservando a autenticidade. Assim sendo, este trabalho analisa o Edifício sede da Câmara Municipal do Recife (CMR) através da "Matriz A\&A", ferramenta desenvolvida por Ferreira (2011), que funde a avaliação de autenticidade e acessibilidade em único instrumento, demonstrando que as características físicas do patrimônio arquitetônico não podem ser um entrave à sua adaptação.

Palavras chave: Acessibilidade; patrimônio cultural; Câmara Municipal; Recife.
\end{abstract}

\begin{abstract}
The brazilian legislation indicates access to the sources of national culture as a right of all, guaranteed by the State. To achieve this goal, it is necessary to suppress architectural barriers, offering the population a safe and autonomous displacement condition. In the case of immovable cultural heritage it should be made accessible preserving the authenticity. Thus, this work analyzes the headquarters building of the City Hall of Recife through the "Matriz A \& A" tool developed by Ferreira (2011), which merges the assessment of authenticity and accessibility into a single instrument, demonstrating that the physical characteristics of the architectural heritage do not may be an obstacle to their adaptation.
\end{abstract}

Keywords: Accessibility; cultural heritage; Town hall; Recife.

\section{INTRODUÇÃO}

A acessibilidade confere à pessoa com deficiência ou mobilidade reduzida a condição de deslocar-se com segurança e autonomia em edificações e equipamentos urbanos, e apesar de ser uma exigência, ao caminhar pela cidade raramente identificam-se rotas acessíveis. Essa situação mostra a dificuldade de locomoção de uma pessoa com deficiência, sendo constantemente necessário o auxílio de outras para desenvolver suas atividades.

Se a essencialidade em tornar os espaços acessíveis é algo pouco compreendido pela população e administradores públicos, talvez por um escasso conhecimento das normas, a complexidade aumenta quando nos referimos aos edifícios que são patrimônio cultural. Nesse caso, devemos preservar e manter a autenticidade da construção ao mesmo tempo em que o adaptamos. Embora pareça difícil, é possível alterar sem interferir em sua condição de patrimônio cultural, e fornecer a toda população, sem exclusão, o direito de acesso às fontes de cultura, que deve ser garantido pelo Estado, como cita a Constituição Federal (1988), em seu artigo 215.

Dessa forma, considerando a garantia de acesso como um direito, e o valor da arquitetura como memória de um período da história, essa pesquisa focará no estudo de caso de um edifício público e casa política: a Câmara Municipal do Recife, onde anteriormente 


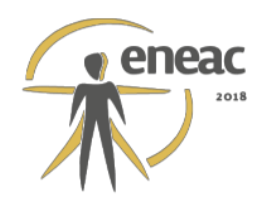

funcionava a Escola Normal Pernambucana e cuja construção é de 1920. Neste período não existia a preocupação em adequar as edificações às pessoas com mobilidade reduzida ou deficiência, apresentando barreiras que dificultam a locomoção, bem como intervenções que podem descaracterizar sua autenticidade. A pesquisa pretende analisar o objeto, identificando as não conformidades com a norma vigente (NBR9050/2015), e auxiliar as futuras propostas de acessibilidade em edifícios de valor histórico, permitindo que todos conheçam a identidade e memória de um povo, através do patrimônio arquitetônico.

\section{FUNDAMENTAÇÃO TEÓRICA}

\subsection{Deficiência e Acessibilidade}

O panorama histórico nos mostra uma evolução nos conceitos e terminologias empregadas para as pessoas com deficiência, partindo de uma conjuntura discriminatória até alcançar uma sociedade preocupada com sua inclusão. No Brasil, segundo Romeu Kazumi Sassaki (2014), até o século XX, os que apresentavam alguma deficiência eram considerados socialmente inúteis e denominados de "os inválidos".

A sociedade passou por uma gradativa evolução de valores, sendo 1981, considerado pela Organização das Nações Unidas (ONU) como o "Ano Internacional das Pessoas Deficientes", gerando discussões sobre a acessibilidade arquitetônica e expondo à população as dificuldades enfrentadas diariamente por essas pessoas. A expressão "Pessoas Deficientes" causou estranheza visto que a sociedade nunca havia se referido às pessoas com deficiência usando a palavra "pessoas", era sempre: "os incapacitados", "os aleijados", "os excepcionais", entre outros. Atualmente a expressão mais adequada é "pessoa com deficiência", empregada no texto da Convenção Internacional sobre os Direitos das Pessoas com Deficiência, realizada em 2006 pela ONU. Essa terminologia enfatiza que os que possuem alguma deficiência são acima de tudo "pessoas", e que a deficiência é somente mais uma característica da condição humana.

No Brasil, em 2004, foi determinada a adoção das normas técnicas de acessibilidade da ABNT na concepção dos projetos arquitetônicos e urbanísticos, através do Decreto n.․․

5.296. A partir de então passou a ser seguida NBR 9050, que teve sua primeira versão criada em 1983, e sofreu posteriormente três revisões: em 1994, 2004 e 2015. A última revisão ainda traz regulamentações referentes ao piso tátil, mas a necessidade de um maior detalhamento ocasionou a criação de uma nova norma de acessibilidade com diretrizes para elaboração de projetos e instalação da sinalização tátil no piso, a NBR 16537/2016.

As últimas décadas foram marcadas por políticas públicas e criação de leis e normas que promovessem a integração das pessoas com deficiência à sociedade, garantindo direitos e condições de igualdade, e buscando eliminar as barreiras arquitetônicas para facilitar a rotina e dia-a-dia desses indivíduos.

\subsection{Patrimônio Cultural}

Em 1931, no período entre duas guerras mundiais, ocorreu a Primeira Conferência Internacional de Museus, que resultou na Carta de Atenas, constatando a ameaça de deterioração dos monumentos de interesse histórico, artístico ou científico, e incentivando a colaboração dos Estados na sua conservação e proteção.

No Brasil, a Constituição de 1934 consagrou a proteção ao patrimônio, e destinou à União e aos Estados competência para "proteger as belezas naturais e os monumentos de valor histórico ou artístico". Mas é em 1937, com a outorga da quarta Constituição Federal do Brasil que a existência do Patrimônio Nacional é oficialmente reconhecida como "o conjunto dos bens móveis e imóveis existentes no país e cuja conservação seja de interesse público, quer por sua vinculação a fatos memoráveis da história do Brasil, quer por seu excepcional valor arqueológico ou etnográfico, bibliográfico ou artístico". Neste mesmo ano é criado o 


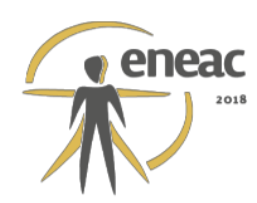

Serviço do Patrimônio Histórico e Artístico Nacional (SPHAN), hoje instituto conhecido como IPHAN.

A Carta de Veneza, em 1964, ampliou a definição de monumento histórico, abrangendo não apenas a edificação ou artefato, mas também seu entorno. A significância cultural, valor histórico e relação de identidade da obra com a sociedade, passaram a ser considerados em detrimento da imponência como única característica.

Em 1972, surgiu o primeiro conceito de patrimônio cultural, como conseqüência da "Convenção para a Proteção do Patrimônio Mundial, Cultural e Natural", em Paris, considerando como patrimônio cultural os monumentos, conjuntos e locais de interesse que apresentam valor universal excepcional do ponto de vista histórico, artístico ou científico, como também estético, etnológico ou antropológico.

A partir de 1988, no Brasil, o conceito referente a patrimônio histórico e artístico foi expandido. A nova Constituição Federal define o patrimônio cultural em seu artigo 216, classificando-o como bens materiais/tangíveis e imateriais/intangíveis. O patrimônio cultural tem seu conceito mantido desde então, e deve ser preservado em sua autenticidade para gerações futuras, pela representatividade como testemunho histórico, significado cultural e identidade com a comunidade.

\subsection{Patrimônio Cultural e Acessibilidade}

Para efeito desta pesquisa, o conceito de autenticidade empregado fundamentou-se na Conferência de Nara (1994), que considera esta a principal característica para atribuição de valores. A pesquisa e o levantamento de informações são indispensáveis para os julgamentos de autenticidade e baseiam-se nos seguintes aspectos: a forma e o desenho, os materiais e a substância, o uso e a função, as tradições e as técnicas, a localização e o espaço, o espírito e o sentimento, como também outros fatores internos e externos.

A carta de Brasília (1995) relaciona o autêntico ao que é verdadeiro, e diz que "a autenticidade se manifesta, se alicerça e se mantém através da veracidade dos patrimônios que recebemos e que transmitimos à posterioridade", sendo essencial ultrapassar a conservação do que é tangível, preservando a memória e as referências culturais. Segundo Beatriz Kühl (2010) autenticidade corresponde ao "respeito pela configuração da obra e pela sua materialidade, como transformadas ao longo do tempo".

No entanto, quando se trata de patrimônio cultural arquitetônico, ao tentar realizar intervenções que assegurem o acesso universal e mantenham a autenticidade do prédio, os arquitetos e profissionais da área se deparam com dúvidas e incertezas. Com o intuito de orientar no que diz respeito a este tema, o IPHAN publicou em 2003, a Instrução normativa no 1 , que dispõe sobre a acessibilidade aos bens culturais imóveis. $O$ texto afirma que os projetos de adaptação devem ser previamente apresentados ao IPHAN para análise e aprovação, e indica que as intervenções devem ser percebidas como adições do tempo presente. O limite para as modificações referentes à acessibilidade estará na "possibilidade de comprometimento do valor testemunhal e da integridade estrutural", porém como não existem regras específicas, cada intervenção é tratada como um caso único.

\section{METODOLOGIA}

O processo metodológico iniciou-se por uma densa pesquisa bibliográfica através de leis, decretos, normas, livros, artigos, dissertações e teses relacionados ao patrimônio cultural, acessibilidade, autenticidade, o edifício da Câmara Municipal do Recife e seu entorno. Esta etapa foi essencial para a fundamentação teórica e conhecimento do objeto de estudo, percebendo seu valor histórico para a sociedade. Concomitantemente foi realizado o levantamento métrico e fotográfico, através de visitas in loco no primeiro semestre de 2017. 


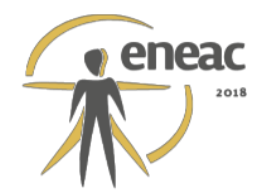

Após a coleta de material iniciou-se a aplicação da "Matriz de Autenticidade e Acessibilidade do Patrimônio Cultural" ou Matriz A\&A, instrumento de avaliação desenvolvido por Ferreira (2011) em sua tese de doutorado, que reúne duas ferramentas em um único instrumento: a Tabela de Autenticidade (Nara-grid) e a Avaliação de Acessibilidade. As informações são cruzadas na matriz prevendo riscos e danos que possam ser gerados no patrimônio ao realizar as adaptações à acessibilidade, ou identificando prejuízos que por ventura tenham sido gerados intervenções mal planejadas. A Matriz A\&A será de grande relevância no direcionamento de futuras adequações que necessitem ser realizadas, contribuindo com a preservação do patrimônio, sua significância, autenticidade e integridade.

\section{EDIFÍCIO SEDE DA CÂMARA MUNICIPAL DO RECIFE E ENTORNO}

O edifício em estudo está localizado no nordeste brasileiro, capital do estado de Pernambuco, Recife, e se situa na Rua Princesa Isabel, transição entre os bairros centrais: Boa Vista e Santo Amaro. A Câmara Municipal faz parte da Zona Especial de Preservação do Patrimônio Histórico - Cultural n¹7 (ZEPH-17), juntamente com duas importantes obras de estimado valor histórico para a cidade: a Faculdade de Direito e o Parque 13 de Maio, sendo essa zona também chamada de "Sítio Histórico Faculdade de Direito".

\section{Figuras 01, 02 e 03: Mapa do Brasil localizando Recife; Mapa dos Bairros; e ZEPH-17.}
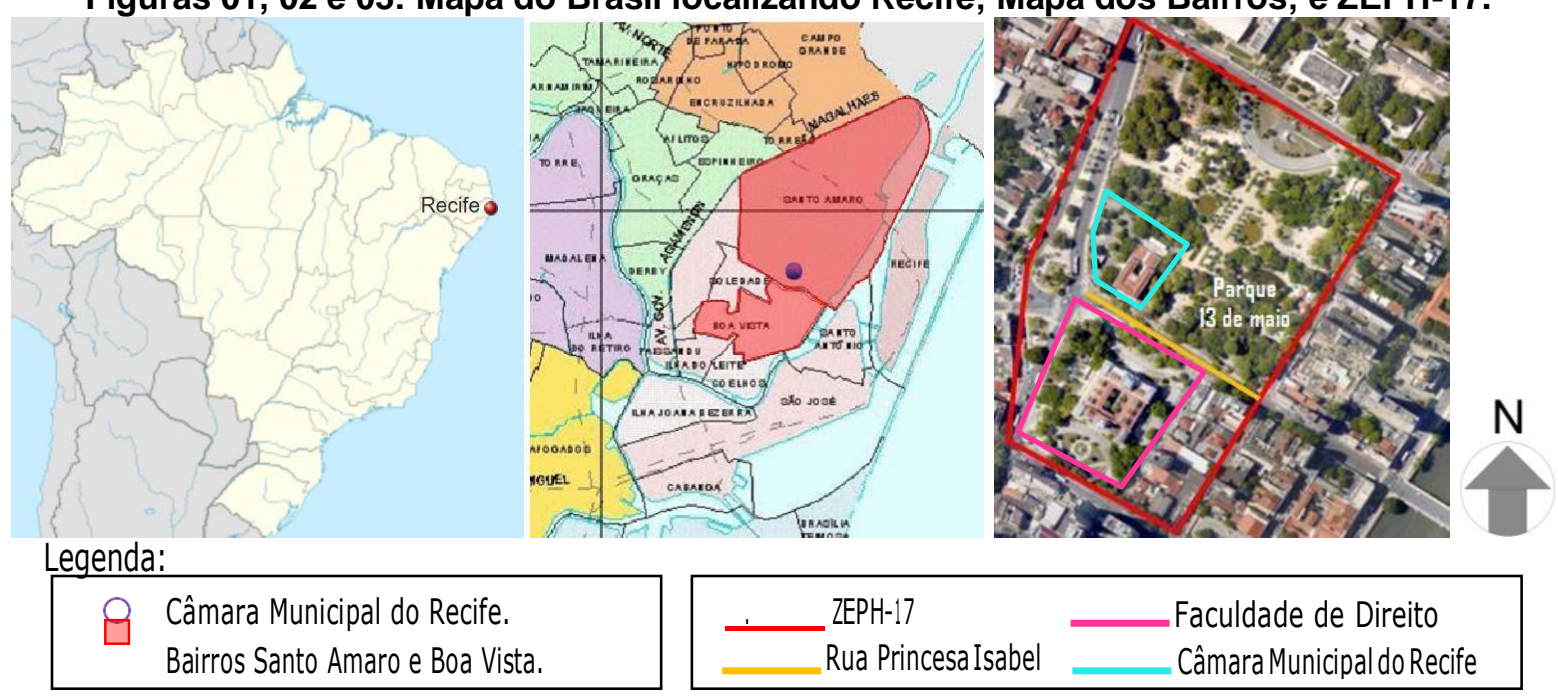

Câmara Municipal do Recife.

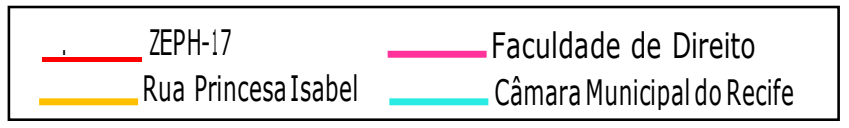

Fonte: Wikipédia; Prefeitura do Recife - ESIG, adaptado.

O prédio da Faculdade de direito é uma construção de arquitetura eclética do engenheiro José Antonio de Almeida e do arquiteto francês Gustave Varin, inaugurado em 1912, quando se tornou um grande referencial arquitetônico. Em 1920, foi construído à sua frente um edifício destinado ao funcionamento da Escola Normal Pernambucana, que também seguiu a linguagem eclética, e onde hoje funciona a Câmara Municipal do Recife, objeto deste estudo. Segundo SILVA (1987, p.181) Pernambuco passou a receber influência direta da Europa com a abertura dos portos brasileiros no início do século XIX, primeiro pela arquitetura neoclássica, e nas duas primeiras décadas do século $X X$ implantando a linguagem eclética, ambas guiadas pelo vocabulário greco-romano.

Em 1939 inaugurou-se o Parque 13 de Maio, de autoria do engenheiro Domingos Ferreira. A demolição da Escola Normal chegou a ser cogitada com o intuito de dedicar uma maior área para esse logradouro público, mas não aconteceu, e em 1963 o prédio passou a ser sede da Câmara Municipal do Recife, denominando-se Casa José Mariano, em homenagem ao abolicionista e atuante político pernambucano. Atualmente a Câmara é representada por 39 vereadores, e tem um quadro de funcionários composto por quase 2.000 pessoas, segundo dados do portal da transparência. 


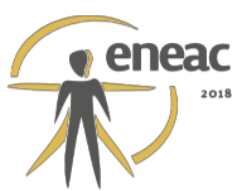

A inserção do objeto de estudo em área de preservação rigorosa demonstra o valor do patrimônio construído e seu entorno para história da cidade, representando um testemunho do passado e devendo ser preservado em sua autenticidade para as gerações futuras.

\section{AVALIAÇÃO DE AUTENTICIDADE}

A avaliação de autenticidade considerou os aspectos: forma e desenho, materiais e substância, uso e função, tradições e técnicas, localização e espaço, espírito e sentimento, conforme Conferência de Nara, em suas dimensões Artística, Histórica, Social e Científica.

\subsection{Forma e Desenho}

A Casa José Mariano apresenta implantação de forma retangular com pátio ao centro da edificação, que gera um espaço de convivência. Os registros encontrados, de fotos e plantas, demonstram que desde a década de 1920 sua configuração se mantém a mesma. Internamente, no entanto, a casa possuía originalmente dois pavimentos com pé direito alto (térreo e primeiro andar), que foram adaptados com a inserção de dois pavimentos intermediários, totalizando quatro (térreo mais três).

Figuras 04 e 05 - Escola Normal (década de 1920) e CMR (atualmente).

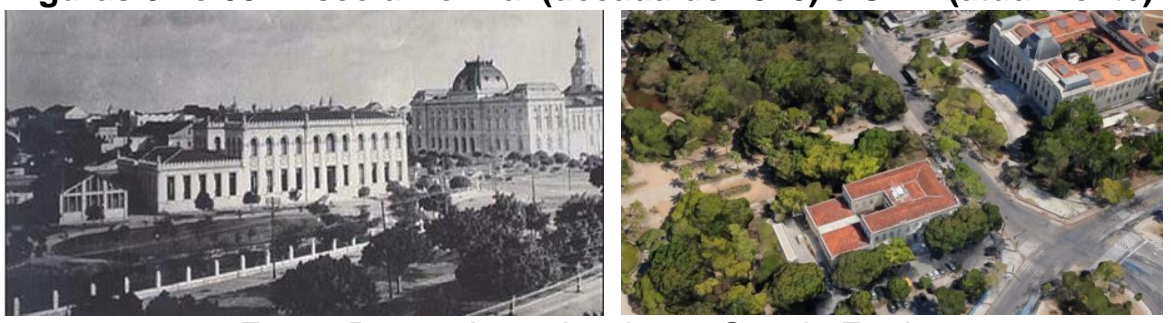

Fonte: Pernambuco Arcaico; e Google Earth.

A fachada ornamentada e simétrica, de arquitetura eclética, retrata o estilo predominante entre o final do século XIX e início do século XX. Entre os elementos arquitetônicos estão: platibanda decorada, arremate em cornija, balcão, molduras nas portas e janelas, luminária e mão francesa em ferro, coluna com capitel coríntio e aplicações em estuque ornamentado. Algumas intervenções prejudicam a leitura da fachada ou a descaracterizam, como as caixas de ar condicionado, dutos e condensadores, assim como as rampas e corrimãos.

Figuras 06, 07 e 08 - Fachada; Corrimão engastado; Equipamentos de ar condicionado.
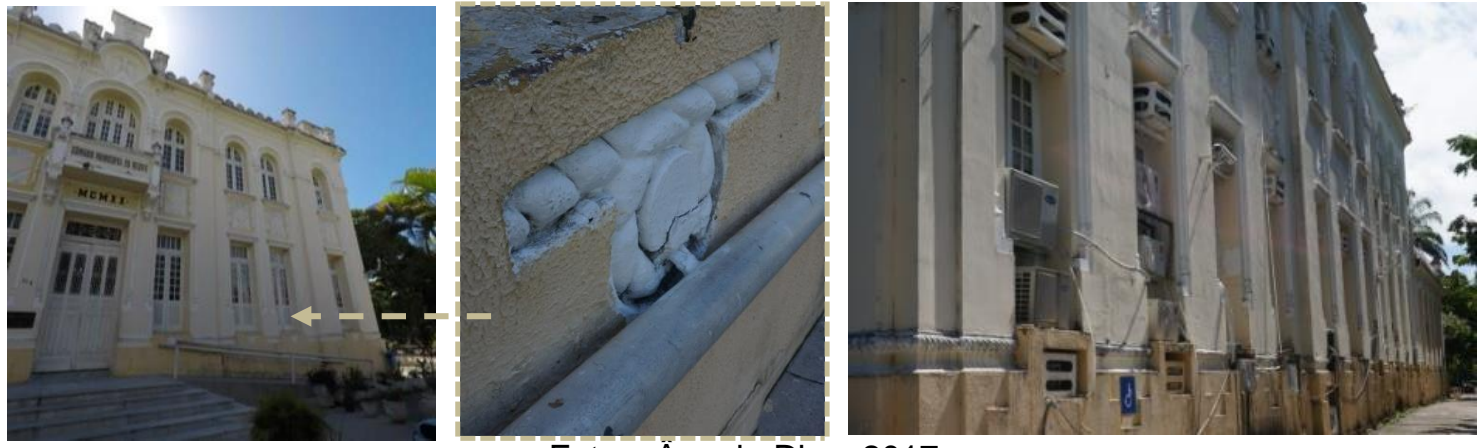

Fotos: Angela Dias, 2017.

\subsection{Materiais e Substância}

A estrutura de vedação da construção é em alvenaria de tijolos de barro cru, o adobe. 0 revestimento é em argamassa de cal e areia, sendo a pintura original à base de cal, que, no entanto passou por diversas alterações, encontrando-se in loco tintas à base de látex PVA e acrílica. A madeira está presente nas esquadrias, na composição da coberta, em alguns pisos e na estrutura criada para os andares intermediários, por onde passam tubulações. 


\subsection{Uso e Função}

O patrimônio arquitetônico em estudo foi construído para abrigar a Escola Normal Oficial de Pernambuco, que se destinava à formação de professores primários, e foi pioneira no preparo pedagógico de pessoas do sexo feminino. Em 1962 iniciaram-se reformas para receber a Câmara dos vereadores, e desde então tem sido cenário de criação de leis, discussões políticas e até mesmo reivindicações da população que busca seus interesses.

A demanda de funcionários e funções foi aumentando com o tempo, e a necessidade por mais espaço levou a intervenções, como a criação de novos pavimentos. Este acréscimo gerou a descontinuidade de portas, janelas e até mesmo de pintura em mural de azulejo (herança da Escola Normal), interceptadas pela estrutura dos pavimentos intermediários. A climatização das salas também gerou danos e poluição visual da fachada, ocasionando recortes nas janelas e paredes para passagem de tubulação e instalação de equipamentos.

\subsection{Tradição e Técnicas}

A técnica construtiva empregada demonstra a influência deixada pelo período colonial através das vedações com sistema de alvenaria de tijolo cru. A coberta estruturada por peças de madeira (tesoura, terças, ripas e caibros) com a telha cerâmica do tipo "francesa" e arrematada por uma platibanda ornamentada, evidencia elementos significantes de autenticidade da edificação. Tubulações de ar-condicionado, porém, cruzam a coberta, e a falta de planejamento, além das freqüentes visitas de técnicos de manutenção ao telhado, geram danos, e por vezes, reparos inapropriados que prejudicam a autenticidade.

\subsection{Localização e Espaço}

O Edifício faz parte de zona de preservação rigorosa com entorno composto por patrimônios de relevante valor histórico para a cidade. Inserido na quadra do parque 13 de maio, é ladeado por densa vegetação, e à sua frente encontra-se o prédio da Faculdade de Direito.

\subsection{Espírito e Sentimento}

O edifício em estudo e seu entorno imediato conferem ao lugar um sentimento de cidade da primeira metade do século XX. Apesar de todas as modificações e modernizações urbanas que ocorreram depois de quase um século, é forte a representatividade dessa área para a história e sociedade. O sentimento e a relação com o passado demonstram a importância em preservar o prédio e seu entorno. No caso específico da CMR sua ligação com a sociedade acontece também através dos serviços prestados, inicialmente como escola de formação pedagógica, e depois como casa política.

\subsection{Tabela de Autenticidade}

Tabela 01 - Tabela de Autenticidade

\begin{tabular}{|c|c|c|c|c|}
\hline \multirow{2}{*}{ Aspectos } & \multicolumn{4}{|c|}{ Dimensões do patrimônio cultural (valores) } \\
\hline & Artística & Histórica & Social & Científica \\
\hline $\begin{array}{l}\text { Forma e } \\
\text { Desenho }\end{array}$ & $\begin{array}{l}\text { A fachada simétrica e } \\
\text { ornamentada, de arquitetura } \\
\text { eclética, apresenta aplicações } \\
\text { de estuques decorativos, } \\
\text { platibanda adornada, cornija, } \\
\text { balcão, molduras nas portas e } \\
\text { janelas, luminária e mão } \\
\text { francesa em ferro, coluna com } \\
\text { capitel coríntio, entre outros. }\end{array}$ & $\begin{array}{l}\text { O desenho ornamentado, } \\
\text { característico da } \\
\text { arquitetura eclética, } \\
\text { simboliza um período da } \\
\text { história do Brasil em que } \\
\text { esse estilo esteve muito } \\
\text { presente (final do século } \\
\text { XIX e início do século } \\
\text { XX). }\end{array}$ & $\begin{array}{l}\text { A forma retangular } \\
\text { com pátio interno } \\
\text { traduz um espaço de } \\
\text { convivência. }\end{array}$ & $\begin{array}{l}\text { A preservação do } \\
\text { edifício sede da CMR e } \\
\text { o prédio da Faculdade de } \\
\text { direito (entorno } \\
\text { imediato) proporcionam } \\
\text { o estudo da produção de } \\
\text { arquitetura eclética em } \\
\text { Pernambuco, no início } \\
\text { do século XX. }\end{array}$ \\
\hline $\begin{array}{l}\text { Materiais e } \\
\text { Substância }\end{array}$ & $\begin{array}{l}\text { As paredes espessas de "adode" } \\
\text { em alvenaria estrutural e a } \\
\text { fachada simétrica com diversos } \\
\text { elementos ornamentais } \\
\text { demonstram a técnica } \\
\text { construtiva e expressão artística } \\
\text { do período. }\end{array}$ & $\begin{array}{l}\text { O uso do tijolo cru em } \\
\text { sistema de alvenaria } \\
\text { estrutural, e revestimento } \\
\text { em argamassa de cal e } \\
\text { areia, demonstram a } \\
\text { tradição construtiva } \\
\text { colonial. A fachada }\end{array}$ & $\mathbf{X}$ & $\begin{array}{l}\text { O edifício sede da CMR } \\
\text { e o prédio da Faculdade } \\
\text { de direito (entorno } \\
\text { imediato) proporcionam } \\
\text { o estudo e } \\
\text { aprofundamento nas } \\
\text { técnicas construtivas e }\end{array}$ \\
\hline
\end{tabular}




\begin{tabular}{|c|c|c|c|c|}
\hline & & $\begin{array}{l}\text { ornamentada e seus } \\
\text { elementos decorativos } \\
\text { remontam ao período da } \\
\text { arquitetura eclética e } \\
\text { introdução de novas } \\
\text { técnicas. }\end{array}$ & & $\begin{array}{l}\text { materiais empregados no } \\
\text { início do século XX, } \\
\text { bem como o traçado e } \\
\text { paisagismo de espaços } \\
\text { públicos (parque } 13 \mathrm{de} \\
\text { maio). }\end{array}$ \\
\hline $\begin{array}{c}\text { Uso e } \\
\text { Função }\end{array}$ & $\begin{array}{l}\text { A função original do edifício, } \\
\text { como instituição de ensino, foi } \\
\text { determinante para a } \\
\text { configuração interna do espaço, } \\
\text { que inclui entradas e halls } \\
\text { amplos, pátio interno e } \\
\text { escadarias para circulação } \\
\text { intensa de pessoas. }\end{array}$ & $\begin{array}{l}\text { Em 1920, quando o prédio } \\
\text { foi construído abrigava a } \\
\text { Escola Normal Oficial de } \\
\text { Pernambuco. A partir de } \\
1963 \text { passa a funcionar } \\
\text { como Câmara dos } \\
\text { Vereadores de Recife. }\end{array}$ & $\begin{array}{l}\text { O edifício em estudo } \\
\text { faz parte da memória } \\
\text { da cidade e sempre } \\
\text { abrigou funções que } \\
\text { serviram à sociedade, } \\
\text { seja como instituição } \\
\text { de ensino ou como } \\
\text { casa política. }\end{array}$ & $\begin{array}{l}\text { O edifício sede da CMR } \\
\text { e o prédio da Faculdade } \\
\text { de direito (entorno } \\
\text { imediato) proporcionam } \\
\text { o estudo de configuração } \\
\text { interna de instituições de } \\
\text { ensino }\end{array}$ \\
\hline $\begin{array}{c}\text { Tradição e } \\
\text { Técnicas }\end{array}$ & $\begin{array}{l}\text { Embora o sistema de vedação } \\
\text { com alvenaria estrutural seja } \\
\text { herança do período colonial, a } \\
\text { arquitetura eclética trouxe } \\
\text { novas técnicas e materiais. Essa } \\
\text { arquitetura recebeu influência } \\
\text { de diversos estilos } \\
\text { arquitetônicos, produzindo uma } \\
\text { fachada ornamentada com a } \\
\text { aplicação de estuques } \\
\text { decorativos, e novas matérias- } \\
\text { prima como o ferro. }\end{array}$ & $\begin{array}{l}\text { O sistema construtivo em } \\
\text { alvenaria estrutural é } \\
\text { herança do período } \\
\text { colonial. A estrutura de } \\
\text { coberta em madeira e } \\
\text { telhas francesa, } \\
\text { arrematadas por uma } \\
\text { platibanda ornamentada } \\
\text { que simbolizam as técnicas } \\
\text { de construção da época. }\end{array}$ & $\mathbf{X}$ & $\begin{array}{l}\text { O edifício da CMR e o } \\
\text { da Faculdade de direito } \\
\text { (entorno imediato) } \\
\text { proporcionam o estudo e } \\
\text { aprofundamento das } \\
\text { técnicas construtivas e } \\
\text { materiais empregados no } \\
\text { início do séc. XX, bem } \\
\text { como o traçado e } \\
\text { paisagismo de espaços } \\
\text { públicos (parque } 13 \text { de } \\
\text { maio). }\end{array}$ \\
\hline $\begin{array}{c}\text { Localização } \\
\text { e Espaço }\end{array}$ & $\begin{array}{l}\text { A inclusão do edifício em zona } \\
\text { de preservação rigorosa } \\
\text { demonstra a importância em } \\
\text { manter suas características, } \\
\text { como parte da história e } \\
\text { produção artística. Não apenas } \\
\text { o edifício da Câmara, como seu } \\
\text { entorno imediato, onde estão a } \\
\text { Faculdade de direito e o Parque } \\
13 \text { de maio, frutos de projetos } \\
\text { arquitetônicos e de engenharia. }\end{array}$ & $\begin{array}{l}\text { O edifício e a relação com } \\
\text { seu entorno imediato } \\
\text { contextualizam um período } \\
\text { da história e fazem parte da } \\
\text { identidade da cidade do } \\
\text { recife. As principais } \\
\text { construções pertencentes } \\
\text { ao "Sítio histórico da } \\
\text { Faculdade de direito" são } \\
\text { da primeira metade do } \\
\text { século XX. }\end{array}$ & $\begin{array}{l}\text { O patrimônio em } \\
\text { estudo, juntamente } \\
\text { com seu entorno } \\
\text { imediato, servem à } \\
\text { sociedade, oferecendo } \\
\text { lazer (Parque } 13 \text { de } \\
\text { maio), ensino } \\
\text { (Faculdade de direito) } \\
\text { e criando leis que } \\
\text { regem a cidade } \\
\text { (CMR). }\end{array}$ & \\
\hline $\begin{array}{c}\text { Espírito e } \\
\text { Sentimento }\end{array}$ & X & $\begin{array}{l}\text { O patrimônio arquitetônico } \\
\text { em estudo tem forte } \\
\text { ligação com a sociedade } \\
\text { também através dos } \\
\text { serviços prestados, } \\
\text { inicialmente como escola } \\
\text { de formação pedagógica, e } \\
\text { depois como casa política. }\end{array}$ & $\begin{array}{l}\text { O edifício e seu } \\
\text { entorno conferem um } \\
\text { sentimento de cidade } \\
\text { da primeira metade do } \\
\text { séc. XX, sendo forte a } \\
\text { representatividade da } \\
\text { área para a história e } \\
\text { sociedade. }\end{array}$ & \\
\hline
\end{tabular}

\section{AVALIAÇÃO DE ACESSIBILIDADE}

A avaliação de acessibilidade focou nas áreas de circulação e de acesso ao público, como banheiros e plenário, sendo realizado um estudo comparativo da situação encontrada no edifício sede da Câmara Municipal do Recife (CMR) e as exigências da NBR9050/2015.

\subsection{Estacionamento}

O edifício sede da CMR possui um total de 134 vagas, sendo 39 destinadas aos vereadores e o restante aos funcionários e visitantes. Destas, apenas uma vaga é para pessoas com deficiência, e está em desacordo com norma. Considerando leis federais e municipais, deveriam ser disponibilizadas 3 (três) vagas para pessoas com deficiência, como também 7 (sete) para idosos e 2 (duas) para gestantes e mães com crianças de até dois anos.

A única vaga existente reservada para pessoas com deficiência, embora localizada próximo à entrada principal do prédio, não oferece rota acessível, nem faixa de circulação livre de obstáculos $(1.20 \mathrm{~m})$. As sinalizações horizontais e verticais estão em desacordo com a Resolução 236/07 e a NBR9050, respectivamente, além da superfície do piso irregular.

Tabela 02 - Quantitativo de vagas exigido por lei. QUANTIDADE DE VAGAS EXIGIDAS POR LEI PESSOA COM

Total de vagas IDOSOS (5\%)

GESTANTE (01/cada 50) DEFICIÊNCIA (2\%)

|LEI FEDERAL № 13.146/2015] [LEI FEDERAL № 10.741/2003]

[LEI MUNICIPAL № 17.298/2007] 
Figura 09 - Vaga pessoa com deficiência.

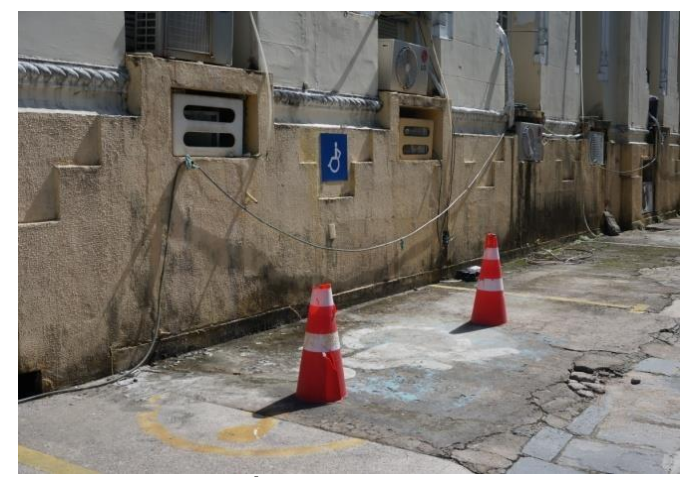

Foto: Ângela Dias, 2017.
Figura 10 - Entradas e acessos.

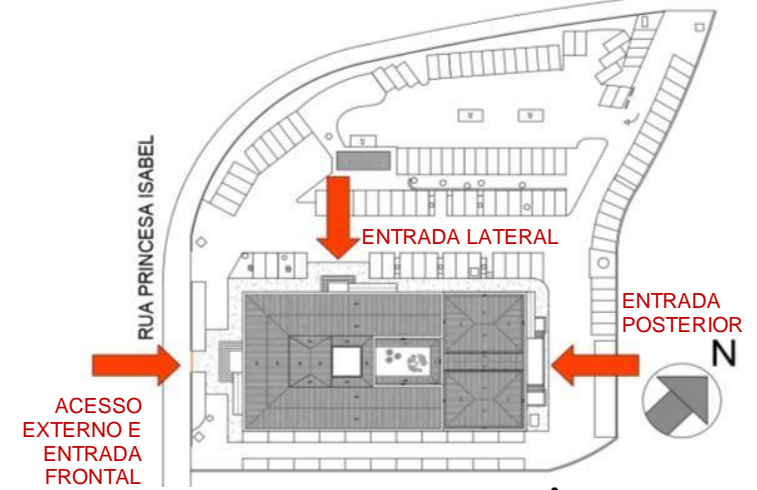

Fonte: CMR, adaptado Ângela Dias.

\subsection{Entradas e Acessos de pedestres}

A CMR apresenta um único acesso de pedestres a partir do passeio público, onde existe uma caixa de inspeção não nivelada ao piso e um desnível de $10 \mathrm{~cm}$. $O$ ingresso para 0 interior do prédio acontece por três entradas, uma frontal, uma lateral e uma posterior, todas com rampas e inclinações superiores a $8,33 \%$ (equivalentes a $11 \%, 10,1 \%$, e 15,91\%, respectivamente), sendo duas delas seguidas por desníveis. Além disso, alguns trechos do passeio têm menos de $1,20 \mathrm{~m}$, dificultando o percurso de acesso até as rampas. Embora a existência das rampas facilite a locomoção de pessoas em cadeiras de rodas (PCR), as situações em desacordo com a norma impossibilitam sua autonomia, visto que a PCR não consegue guiar sua própria cadeira sem auxílio.

\subsection{Rampas}

As rampas das três entradas principais do prédio estão em desacordo com a norma, conforme descrito no item anterior. Ao andar pelo edifício encontram-se rampas provisórias que podem se tornar obstáculos e provocar acidentes. No passeio ao redor do prédio verifica-se a presença de rampa que deveria funcionar como rebaixamento de calçada e seguir o dimensionamento exigido pela NBR 9050.

Figuras 11, 12 e 13 - Rampas em desacordo com a NBR 9050/2015.

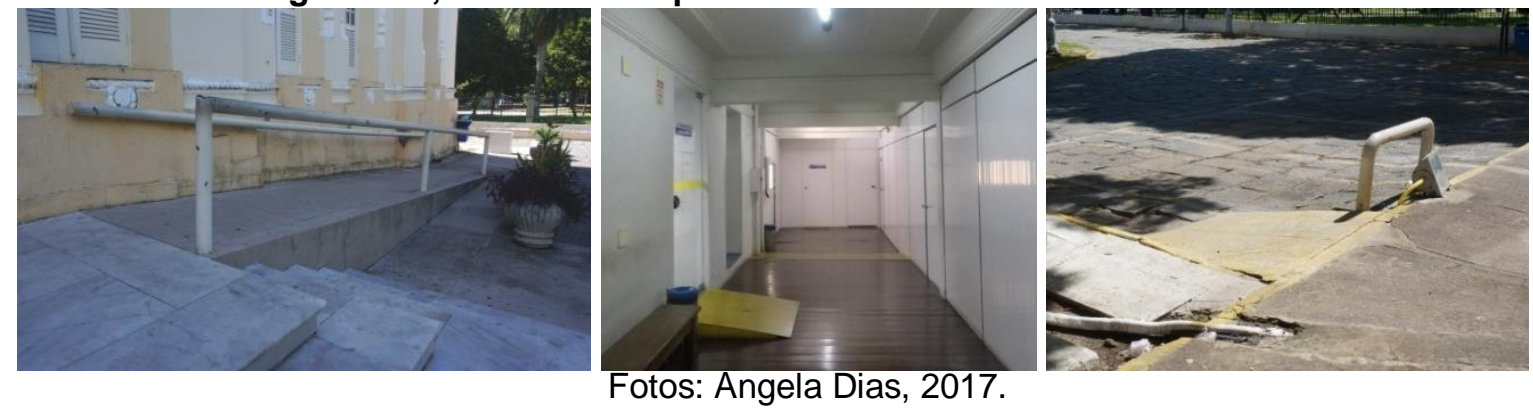

\subsection{Escadas e Circulação Vertical}

A CMR possui circulação vertical do pavimento térreo para os demais andares através de escada e elevador. porém, Como dito no decorrer do trabalho, originalmente o edifício era composto por térreo e primeiro andar, ambos com pé direito duplo. Devido à necessidade de mais espaço foram construídos pavimentos intermediários $O$ elevador existente continua fazendo ligação apenas entre os dois andares da configuração original (térreo e o atual $2^{\circ}$ pavimento), situação que dificulta ou mesmo impossibilita o acesso aos demais pavimentos pelas pessoas com mobilidade reduzida (PMR) e em cadeira de rodas (PCR).

As escadas, por sua vez, não possuem precisão na dimensão dos pisos e espelhos, provocando a descontinuidade na passada e uma conseqüente possibilidade de quedas. 


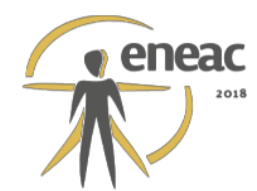

Além da existência de pisos quebrados e falta de corrimão. A sinalização visual das escadas é inexistente ou em desacordo com a norma.

Figuras 14, 15, 16 e 17 - Degraus de escadas com pisos danificados.
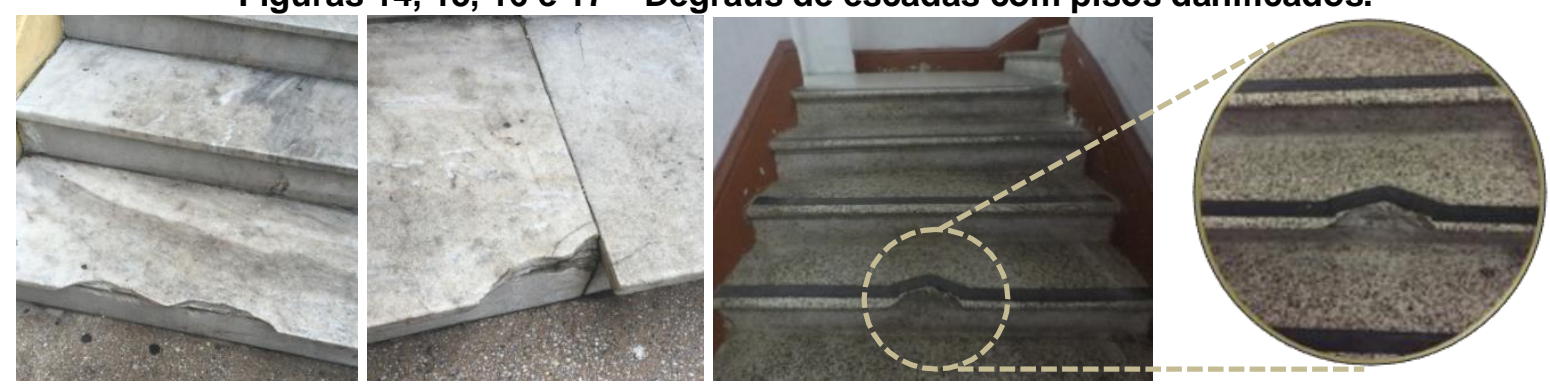

Fotos: Ângela Dias, 2017.

Uma das situações mais críticas de circulação vertical está no plenário, cujo acesso para galerias e tribuna acontece apenas através de escadas. Em dias de sessões plenárias, nas quais os vereadores discutem e votam os projetos, a participação de pessoas em cadeiras de rodas e com mobilidade reduzida é dificultada devido à ausência de espaços acessíveis reservados. A mesma problemática é enfrentada em sessões solenes, quando o homenageado apresenta deficiência física e precisa ir à tribuna proferir seus agradecimentos. Em ambos os casos a PCR e PMR necessita de auxílio de outros indivíduos, causando constrangimento.

Figura 18 e 19 - Plenário e acessos por escada.

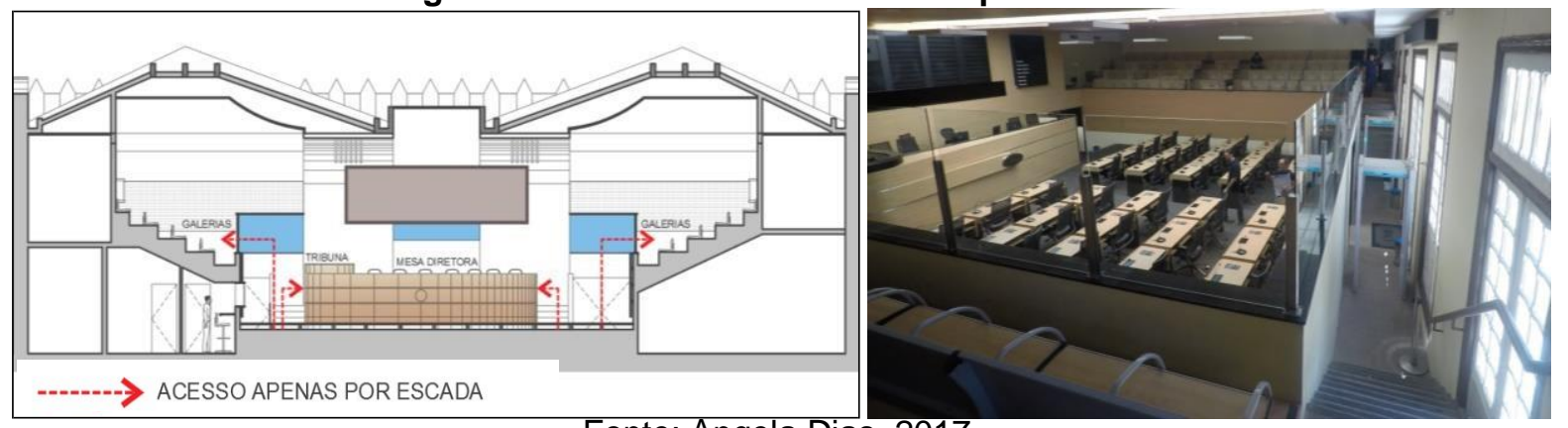

Fonte: Angela Dias, 2017.

\subsection{Corrimãos}

Não foram encontrados corrimãos que seguissem a NBR9050/2015. Entre as não conformidades estão: corrimão com apenas uma altura ou altura inadequada, seção circular de $80 \mathrm{~mm}$ (superior ao indicado na norma), instalação em apenas um dos lados da rampa ou escada, extremidades sem acabamento recurvado, assim como ausência de corrimão.

Figuras 20, 21, 22 e 23 - Escadas e corrimãos fora do padrão exigido pela NBR 9050/2015.
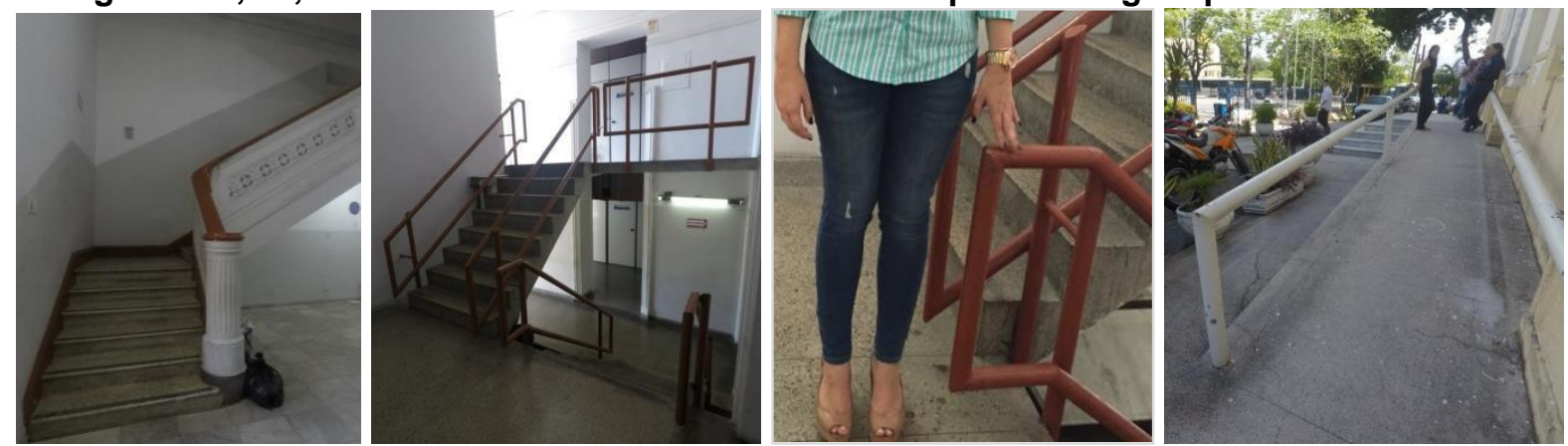

Fotos: Ângela Dias, 2017. 


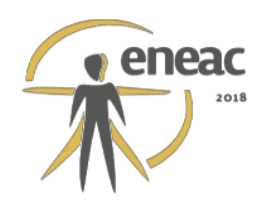

\subsection{Pisos}

Ao percorrer a área externa e o interior do prédio encontramos diversas irregularidades nos pisos, como trincas e quebras. Os pavimentos intermediários ( $1^{\circ}$ e 3 andar), que foram inseridos posteriormente, têm circulação em réguas de madeira que apresentam instabilidade e trepidação. Essa condição gera riscos de queda, podendo se agravar quando os pedestres que as percorrem são pessoas com deficiência física ou visual.

Figuras 24, 25, 26 e 27 - Pisos com superfície irregular.

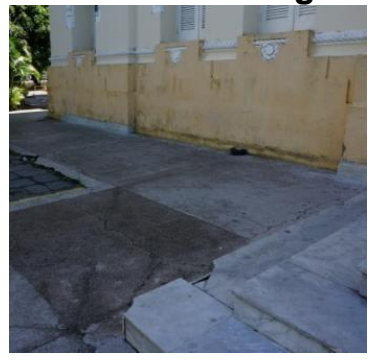

\subsection{Desníveis}
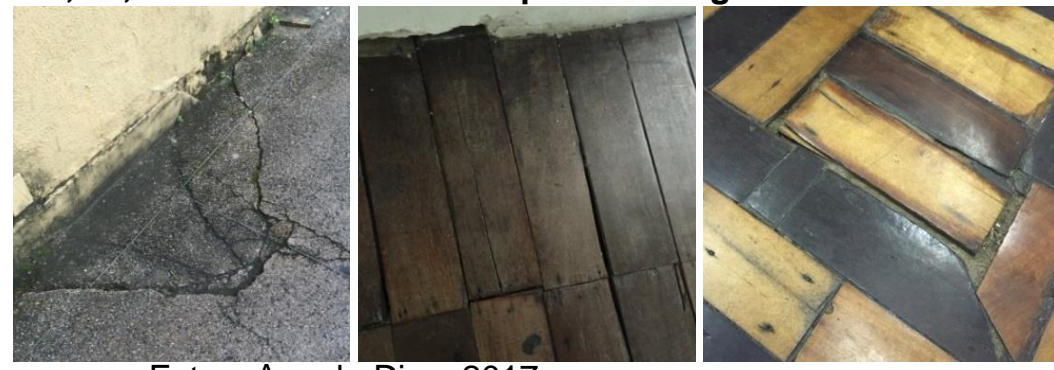

Fotos: Angela Dias, 2017.

No edifício em estudo foram encontrados diversos desníveis com dimensões acima do indicado pela NBR 9050, atingindo até $17 \mathrm{~cm}$, impedindo uma circulação segura e com autonomia às pessoas com deficiência e mobilidade reduzida.

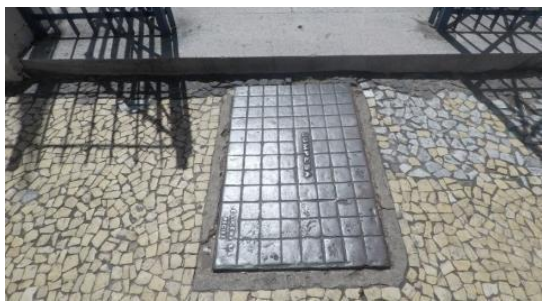

Figuras 28, 29 e 30 - Desníveis
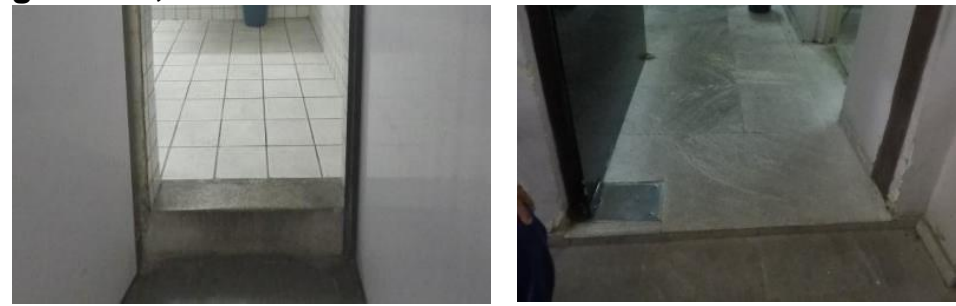

Fotos: Ângela Dias, 2017.

\subsection{Sinalização tátil e visual}

Não existe sinalização tátil de nenhuma espécie no edifício, nem de alerta e nem direcional, dificultando deslocamento e a orientação de pessoas com deficiência visual.

\subsection{Banheiros}

O prédio não possui nenhum banheiro acessível, e de acordo com a NBR9050/2015 edifícios públicos existentes, devem incluir um sanitário acessível por pavimento. Entre as exigências não atendidas podemos citar a ausência de barras de apoio, de área de transferência e de circulação com giro de $360^{\circ}$, instalação de equipamentos fora do alcance manual e visual, além de lavatórios e bacias sanitárias com dimensões inadequadas.

Figuras 31, 32 e 33 - Banheiros da CMR.
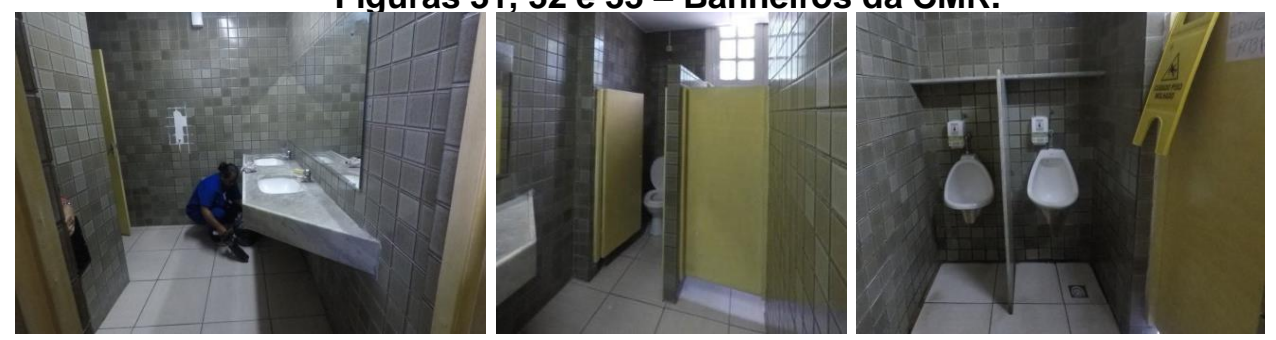

Fotos: Ângela Dias, 2017. 


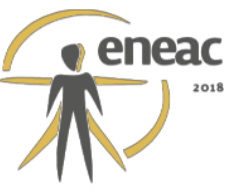

\section{MATRIZ DE AUTENTICIDADE E ACESSIBILIDADE}

Tabela 03 - Matriz de Autenticidade \& Acessibilidade

\begin{tabular}{|c|c|c|c|c|}
\hline \multirow{2}{*}{ Aspectos } & \multicolumn{4}{|c|}{ Dimensões } \\
\hline & Artística & Histórica & Social & Científica \\
\hline $\begin{array}{l}\text { Forma e } \\
\text { Desenho }\end{array}$ & $\begin{array}{l}\text { As rampas e corrimãos instalados } \\
\text { no edifício não atendem à norma. } \\
\text { O corrimão, chumbado na parede } \\
\text { danifica os elementos da fachada. } \\
\text { É possível adequar algumas } \\
\text { rampas à inclinação exigida em } \\
\text { norma, de forma a garantir ao } \\
\text { máximo a leitura da fachada e } \\
\text { não danificar características do } \\
\text { imóvel. Embora possa } \\
\text { descaracterizar um pouco, as } \\
\text { rampas se fazem necessárias pelo } \\
\text { uso público do edifício. }\end{array}$ & $\begin{array}{l}\text { A inserção de novos } \\
\text { elementos no prédio deve } \\
\text { utilizar-se de materiais que } \\
\text { permitam a diferenciação } \\
\text { entre o novo e o antigo. É o } \\
\text { caso dos corrimãos que } \\
\text { devem ser incluídos de } \\
\text { acordo com a norma de } \\
\text { acessibilidade. }\end{array}$ & $\begin{array}{l}\text { A inclusão de um } \\
\text { espaço acessível às } \\
\text { PCR e PMR no } \\
\text { plenário não faria } \\
\text { alterações que } \\
\text { interferissem na forma } \\
\text { e desenho do prédio, } \\
\text { visto que o interior do } \\
\text { plenário já não } \\
\text { conserva } \\
\text { características do } \\
\text { passado. }\end{array}$ & $\mathbf{X}$ \\
\hline $\begin{array}{l}\text { Materiais e } \\
\text { Substância }\end{array}$ & $\begin{array}{l}\text { As adaptações à acessibilidade } \\
\text { que necessitem da inserção de } \\
\text { novos elementos e materiais no } \\
\text { prédio devem ser eficazes quanto } \\
\text { à distinção entre o atual e o } \\
\text { antigo. }\end{array}$ & $\begin{array}{l}\text { Grande parte dos pisos do } \\
\text { prédio apresenta quebras e } \\
\text { superfícies irregulares. Os } \\
\text { identificados como originais } \\
\text { da época de construção } \\
\text { devem ser mantidos e } \\
\text { restaurados, reconstituindo as } \\
\text { partes danificadas. Os pisos } \\
\text { quebrados de mármore } \\
\text { podem ser substituídos pela } \\
\text { mesma pedra, seguindo a } \\
\text { configuração original. }\end{array}$ & $\begin{array}{l}\text { A inclusão de } \\
\text { sinalização tátil de } \\
\text { alerta e direcional e a } \\
\text { reconstituição dos } \\
\text { pisos danificados no } \\
\text { prédio, facilitariam a } \\
\text { circulação de pessoas } \\
\text { com deficiência no } \\
\text { edifício e não } \\
\text { alterariam } \\
\text { significativamente sua } \\
\text { leitura. }\end{array}$ & $\begin{array}{l}\text { O estudo e registro } \\
\text { dos materiais e } \\
\text { técnicas construtivas } \\
\text { utilizadas no prédio } \\
\text { podem auxiliar as } \\
\text { futuras intervenções. } \\
\text { Principalmente por } \\
\text { se tratar de uma casa } \\
\text { política, que sua } \\
\text { administração } \\
\text { alterada a cada } \\
\text { quatro anos. }\end{array}$ \\
\hline $\begin{array}{l}\text { Uso e } \\
\text { Função }\end{array}$ & $\begin{array}{l}\text { O novo uso dado ao prédio } \\
\text { (alterado de escola para casa } \\
\text { política) e a necessidade de mais } \\
\text { espaço, levou à inserção de } \\
\text { pavimentos intermediários. É } \\
\text { preciso fazer um estudo da } \\
\text { possibilidade de trocar o elevador } \\
\text { existente por um acessível e com } \\
\text { paradas em todos os pavimentos, } \\
\text { aproveitando o mesmo fosso. No } \\
\text { caso de inviabilidade, outra } \\
\text { solução seria colocar um elevador } \\
\text { panorâmico na área do pátio } \\
\text { interno, diferenciando o novo e o } \\
\text { antigo. }\end{array}$ & $\begin{array}{l}\text { Algumas tecnologias } \\
\text { surgiram e foram } \\
\text { popularizadas após a } \\
\text { construção do prédio, como o } \\
\text { ar-condicionado. A inclusão } \\
\text { deste equipamento na } \\
\text { fachada dificultou sua leitura } \\
\text { e danificou elementos de } \\
\text { valor testemunhal. É } \\
\text { necessário fazer um estudo } \\
\text { para retirar as caixas de ar- } \\
\text { condicionado e } \\
\text { condensadores das fachadas } \\
\text { principais, de forma a } \\
\text { valorizar e facilitar a leitura } \\
\text { da fachada. }\end{array}$ & $\begin{array}{l}\text { A realização das } \\
\text { adaptações de rampas, } \\
\text { elevadores, desníveis e } \\
\text { pisos danificados } \\
\text { permitirão o acesso de } \\
\text { todos ao prédio, e são } \\
\text { essenciais devido ao } \\
\text { seu uso (edifício } \\
\text { público e casa } \\
\text { política). Estas } \\
\text { modificações vão } \\
\text { favorecer a } \\
\text { participação da } \\
\text { população nas } \\
\text { questões políticas } \\
\text { municipais. }\end{array}$ & \\
\hline $\begin{array}{l}\text { Tradição e } \\
\text { Técnicas }\end{array}$ & $\begin{array}{l}\text { Utilizar tradição e técnicas do } \\
\text { período de construção para a } \\
\text { restauração de esquadrias, pisos e } \\
\text { ornamentos danificados. Tais } \\
\text { danos são consequiências da } \\
\text { inserção de ar-condicionado, da } \\
\text { intensa circulação de pessoas, do } \\
\text { corrimão engastado na fachada, } \\
\text { entre outros. }\end{array}$ & $\begin{array}{l}\text { A restauração e substituição } \\
\text { dos ornamentos, esquadrias e } \\
\text { pisos danificados que sejam } \\
\text { da época de construção } \\
\text { exigirão o estudo das } \\
\text { técnicas a serem usadas. }\end{array}$ & ( & $\begin{array}{l}\text { O estudo e registro } \\
\text { dos materiais e } \\
\text { técnicas construtivas } \\
\text { utilizadas auxiliarão } \\
\text { futuras intervenções. } \\
\text { Principalmente por } \\
\text { ser casa política, } \\
\text { cuja administração } \\
\text { muda a cada quatro } \\
\text { anos. }\end{array}$ \\
\hline $\begin{array}{c}\text { Localização } \\
\text { e Espaço }\end{array}$ & $\begin{array}{l}\text { As adaptações não devem alterar } \\
\text { sua relação com as edificações do } \\
\text { entorno, por isso toda mudança } \\
\text { deve ser analisada e realizada de } \\
\text { modo a não interferir nas } \\
\text { construções pertencentes ao } \\
\text { "Sítio histórico da Faculdade de } \\
\text { direito". }\end{array}$ & $\mathbf{X}$ & $\mathbf{X}$ & \\
\hline $\begin{array}{c}\text { Espírito e } \\
\text { Sentimento }\end{array}$ & $\mathbf{X}$ & $\begin{array}{l}\text { As inserções e adaptações } \\
\text { devem ser estudadas com } \\
\text { cautela para que se mantenha } \\
\text { a relação do edifício e seu } \\
\text { entorno, permitindo a } \\
\text { diferenciação entre o antigo e } \\
\text { novo, cultivando o } \\
\text { sentimento e espírito de } \\
\text { cidade da primeira metade do } \\
\text { século XX, sem confundir-se } \\
\text { com o incluído no séc. XXI. }\end{array}$ & $\mathbf{X}$ & $\mathbf{X}$ \\
\hline
\end{tabular}




\section{CONSIDERAÇÕES FINAIS}

A pesquisa mostrou que é possível excluir barreiras arquitetônicas e fornecer acesso às pessoas com deficiência e com mobilidade reduzida, preservando a autenticidade do Patrimônio cultural imóvel. Para que isso ocorra é necessário aprofundar-se no estudo da história e características arquitetônicas do objeto, e identificar as não conformidades com a norma de acessibilidade (NBR9050/2015). Na análise da Câmara Municipal utilizou-se a tabela de autenticidade (Nara-grid), considerando os aspectos: forma e desenho, materiais e substância, uso e função, tradições e técnicas, localização e espaço, espírito e sentimento.

As avaliações de autenticidade e acessibilidade proveram conhecimento e informações sobre o objeto deste estudo, no que diz respeito aos valores que marcam sua autenticidade, as intervenções que o descaracterizam, e a identificação das barreiras arquitetônicas. No que se refere à autenticidade foram percebidos elementos que dificultavam a leitura da fachada, como ar-condicionado e sua tubulação, e os que danificavam a estrutura ou ornamentos do prédio, como os corrimãos engastados. Quanto à acessibilidade, identificaram-se obstáculos, e adaptações realizadas que não seguiam as exigências da norma técnica, como rampas com inclinação superior ao permitido, desníveis, corrimãos fora do padrão ou ausentes, banheiros inacessíveis e falta de sinalização.

A aplicação da Matriz de Autenticidade e Acessibilidade fundiu essas informações em uma única tabela, relacionando e identificado como as adaptações da acessibilidade interferiram, ou interferirão, em sua autenticidade. No caso do edifício sede da Câmara Municipal do Recife, através da pesquisa bibliográfica e da aplicação da matriz percebeu-se a importância em preservar sua arquitetura eclética e a relação com as edificações do entorno imediato. A Matriz A\&A mostrou-se eficaz no auxílio à adequação do Patrimônio Cultural arquitetônico, direcionando a uma intervenção que considere a preservação do seu valor testemunhal.

\section{REFERÊNCIAS BIBLIOGRÁFICAS}

ASSOCIAÇÃO BRASILEIRA DE NORMAS TÉCNICAS - ABNT. NBR 9050: Acessibilidade a edificações, mobiliário, espaços e equipamentos urbanos. Rio de Janeiro, 2015.

BRASIL. Legislação. DECRETO-LEI № 25, DE 30 DE NOVEMBRO DE 1937. Organiza a proteção do patrimônio histórico e artístico nacional. Diário Oficial [da] República Federativa do Brasil, Poder Executivo, Brasília, DF, 06 dez. 1937.

BRASIL. Constituição (1988). Constituição da República Federativa do Brasil. Brasília, DF: Senado Federal, Centro Gráfico, 1988.

CHOAY, Françoise. A alegoria do patrimônio. Tradução: Luciano Vieira Machado. 3ed. São Paulo: Estação Liberdade, UNESP, 2006.

FERREIRA, Oscar Luís. Patrimônio Cultural e Acessibilidade: As intervenções do Programa Monumenta, de 2000 a 2005. Tese (Doutorado em Arquitetura e Urbanismo), UnnB, Brasília, 2011. Disponível em: <http://repositorio.unb.br/handle/10482/9381 > Acesso: 20/01/2017

INSTITUTO DO PATRIMÔNIO HISTÓRICO E ARTÍSTICO NACIONAL. Cartas Patrimoniais.

Brasília: IPHAN, 1995. Disponível em: <http://portal.iphan.gov.br/pagina/detalhes/226> Acesso: 10/05/2017

INSTITUTO DO PATRIMÔNIO HISTÓRICO E ARTÍSTICO NACIONAL. Instrução Normativa n.․․ 1, de 25 de novembro de 2003. Dispõe sobre a acessibilidade aos bens culturais imóveis acautelados em nível federal, e outras categorias, conforme especifica.

KÜHL, Beatriz Mugayar. Notas sobre a Carta de Veneza. Anais do Museu Paulista, São Paulo, v. 18, n. 2, p. 287-320, dez. 2010. Disponível em:

<http://www.revistas.usp.br/anaismp/article/view/5539/7069> Acesso: 11/05/2017

RECIFE. Lei $n^{\circ} 16.176$ de 1996. Estabelece a Lei de Uso e Ocupação do Solo da Cidade do Recife.

Diário Oficial de Recife, Poder Executivo, Recife, PE, 09 abr. 1996.

SASSAKI, Romeu Kazumi. Como chamar as pessoas que têm deficiência? Revista da Sociedade Brasileira de Ostomizados, ano I, n. 1, $1^{\circ} \mathrm{sem}$. 2003, p.8-11. [Texto atualizado em 2014] Disponível em: <http://diversa.org.br/artigos/como-chamar-pessoas-que-tem-deficiencia/> Acesso: 10/05/2017

SILVA, Geraldo Gomes da. Arquitetura Eclética em Pernambuco. In: FABRIS, Annateresa (org.).

Ecletismo na Arquitetura Brasileira. São Paulo: Nobel EDUSP, 1987. 